\title{
Better Understanding the Catastrophe Risk in Interconnection and Comprehensive Disaster Risk Defense Capability, with Special Reference to China
}

\author{
Feng Kong $1,2, * \mathbb{1}$ and Shao Sun ${ }^{3, * \mathbb{D}}$ \\ 1 College of Humanities and Development Studies, China Agricultural University, Beijing 100083, China \\ 2 Center for Crisis Management Research, Tsinghua University, Beijing 100084, China \\ 3 National Climate Center, China Meteorological Administration, Beijing 100081, China \\ * Correspondence: kongfeng0824@cau.edu.cn (F.K.); sunshao@cma.gov.cn (S.S.)
}

Citation: Kong, F.; Sun, S. Better

Understanding the Catastrophe Risk in Interconnection and

Comprehensive Disaster Risk Defense Capability, with Special Reference to China. Sustainability 2021, 13, 1793.

https://doi.org/10.3390/su13041793

Academic Editor:

Abdollah Shafieezadeh

Received: 9 December 2020

Accepted: 5 February 2021

Published: 7 February 2021

Publisher's Note: MDPI stays neutral with regard to jurisdictional claims in published maps and institutional affiliations.

Copyright: (c) 2021 by the authors. Licensee MDPI, Basel, Switzerland. This article is an open access article distributed under the terms and conditions of the Creative Commons Attribution (CC BY) license (https:// creativecommons.org/licenses/by/ $4.0 /)$.

\begin{abstract}
Catastrophe risk governance has become one of the key issues affecting global sustainable development. As great changes have taken place in the global social ecosystem, the degree of interconnection between different regions in today's society is much greater than ever before. Various types of contact networks, e.g., the production chain and supply chain, have been created, which provide diversified channels for the spread of catastrophe risk across time and space. In the context of interconnection, this paper first analyzes the drastic changes of the current disaster risk system. Severe catastrophe risk has posed a great threat to the highly growing international trade, and has also tested the capabilities of national comprehensive disaster defense. Thus, this paper analyzes the main characteristics of China's comprehensive disaster defense capability, including physical, social, and humanistic defense capability. Finally, this paper puts forward the key points to resolve catastrophe risk from the perspective of decision-makers, including improving the decision-makers ability to study and judge the catastrophe chain and the impact of catastrophe, and the national resource reserve capacity to cope with the catastrophe.
\end{abstract}

Keywords: catastrophe risk; comprehensive disaster defense capability; climate change risk; interconnection in globalization; China

\section{Introduction}

With the rapid development of urbanization, industrialization, informatization, global climate change, and agricultural modernization [1-3], the Earth's system has entered the Anthropocene era [4,5]. In the Anthropocene era, affected by various problems related to population, resources, environment and development, the disaster risk system is undergoing great changes in evolution processes and occurrence mechanisms [6].

The structure of a disaster risk system is mainly composed of a disaster-formative environment, hazards, and exposures [7]. The dramatic increases in the depth and breadth of human activities have deeply influenced the natural and humanistic disaster-formative environments [8]. The instability of the natural and humanistic disaster-formative environments are greatly increasing through the process of "gradual change, accumulation, mutation" [7,9]. The frequencies and durations of various kinds of hazards are increasing in the Anthropocene era $[7,10]$. Moreover, the induced phenomenon and coupling effect between different kinds of hazards are increasing [11]. The exposures are affected by many factors, and they are changing unevenly in time and space [12]. With the development of the social economy, the field and scope of exposures are continuing to expand, which lead to an increase in government and social investment in disaster risk management [13]. At the same time, the interaction and coupling among disaster-formative environment, hazards, and exposures tend to be complicated [14]. The complex disaster phenomenon such as disaster chains, multi-hazards, and compound disasters have increased more than 
ever before, which have affected the social ecosystem through a comprehensive process in the form of dynamic and non-dynamic effects [15].

Within the context of a widening economic gap between different regions and frequent global governance failures, the significant changes in the above-mentioned disaster risk system lead more easily to global super risks. Moreover, further coupling effects of different disasters are generated among different systems in the form of triggering, transferring, superimposing, and expanding ripples, which will trigger various kinds of risk management problems of huge space-time, and lead to unprecedented challenges of disaster management research and practice [7]. In this paper, disaster risk is a general term for disaster risk including catastrophe risk. Catastrophe risk refers to the disaster risk with large casualties or economic losses, and has great impact on the social ecosystem $[10,16]$.

At present, most disaster risk scholars believe that the current catastrophe risk is increasing, and try to evaluate whether the disaster defense capability of human society can effectively deal with the catastrophe risk $[6,15,17]$. The practitioners of disaster risk management are also taking engineering measures, as well as catastrophe insurance, catastrophe lottery and catastrophe bonds and other non-engineering measures to deal with the catastrophe risk [15]. They are trying to find out the shortcomings of catastrophe risk prevention in human society. There are some gaps in management, engineering, science and cognition, which lead to the impact of uncertainty and catastrophic nature of catastrophe risk. Therefore, it is urgent to resolve catastrophe risk.

How does catastrophe risk change in the context of interconnection? What is the comprehensive disaster defense capability of human society? How can we effectively resolve catastrophe risk (Figure 1)? These questions are the focus of current academic and practical circles. They are also the main problems that this paper attempts to elaborate upon. The interconnection in this paper refers to the flow and exchange of population, goods, wealth, information and ideas between a specific region and other regions of the world through various kinds of contact networks, such as production chain, supply chain, and value chain, etc. The dependence between regions in the context of interconnection are greatly increasing compared with previous time periods [10]. Disaster risk systems are undergoing significant changes. Coupled with the rapid development of global trade in recent decades, this has brought serious catastrophe risk to the global economy. Can the existing disaster defense capabilities of human society effectively deal with catastrophe risks (Figure 1)? The goal of this paper is to take the theoretical and practical development of China's comprehensive disaster defense capability as an example, and try to find out how to prevent and resolve catastrophe risk in the context of interconnection between China and other regions of the world (Figure 1). In order to achieve this goal, this paper first analyzes the complexity characteristics of catastrophe risk. Then this paper deeply analyzes the potential impact of a disaster risk system on international trade. Then, this paper analyzes the main characteristics of China's disaster defense capability from the perspectives of physical, social, and humanistic defense capabilities. Finally, this paper puts forward three key points to prevent and resolve catastrophe risk in China (Figure 1). 


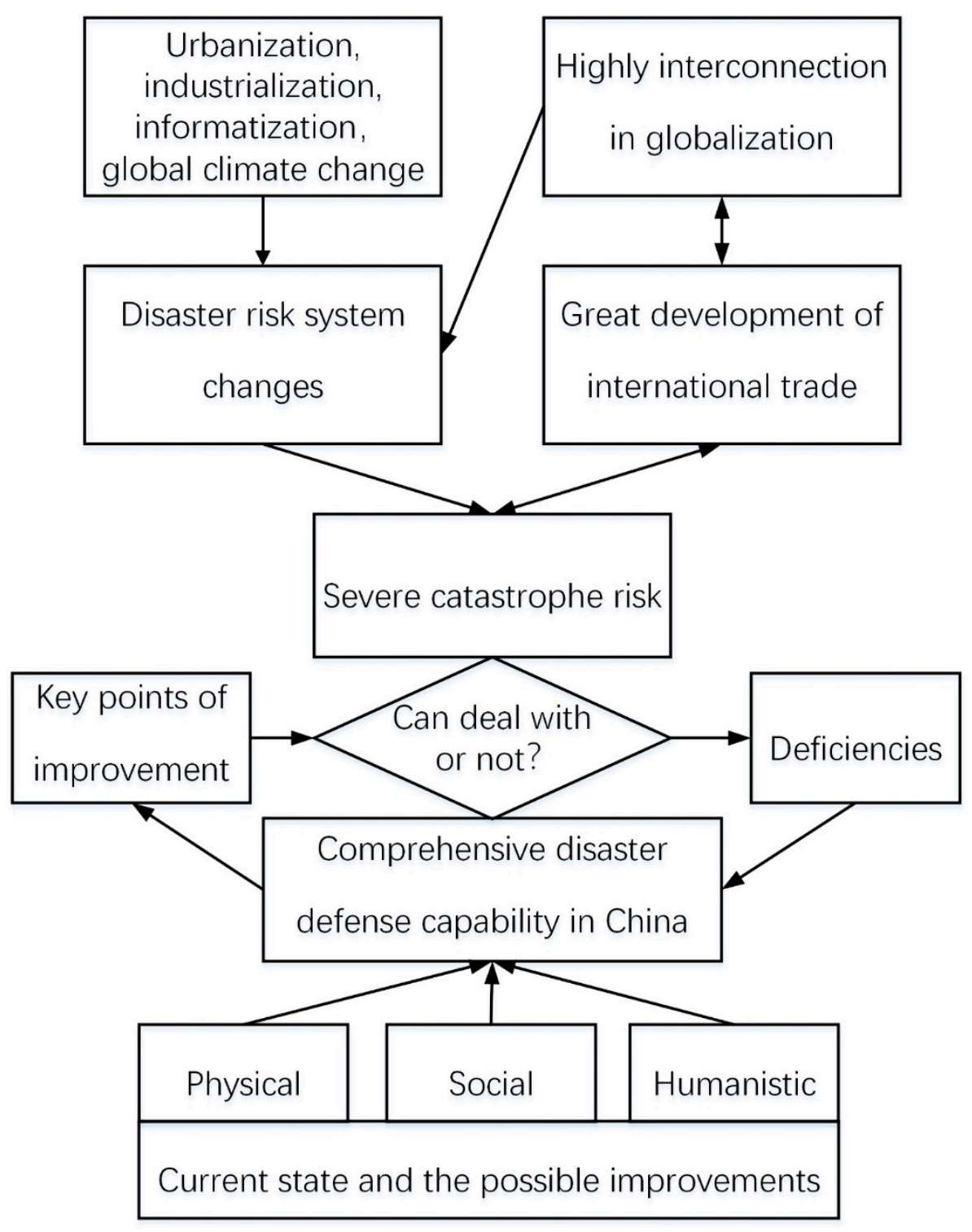

Figure 1. Catastrophe risk in interconnection and comprehensive disaster defense capability.

\section{Disaster Risk Factors Brought by Interconnection}

Various types of contact networks have emerged in the context of interconnection. The most typical contact networks are production chains and supply chains. Interconnection is increasing rapidly in the global social ecosystem $[18,19]$. Whether there is interdependence, trade, information and personnel exchanges and telecommunications networks in a regional economy in the humanities, or biological and abiotic processes in the natural field, the connectivity between the above two aspects is gradually strengthening [20].

Increasing connectivity has many different meanings for the resilience of the global social ecosystem [21]. The dramatic increasing of connectivity is not only conducive to the more rapid spread of information, population and decision-making, but also leads to the faster spread of viruses and diseases. The global COVID-19 epidemic in 2020 is a potent example of this. To some extent, the accelerated development of interconnection is essential for enhancing global and systematic risk prevention. At the same time, high connectivity has other impacts on risk prevention. In the context of interconnection, riots and risks can quickly transfer between the global markets and society, and they are currently undergoing the process of change [15]. It is difficult for human beings to really understand their structural and functional characteristics. As a result, the place where the disaster risk 
occurs and the area that is finally affected will be far apart, and there may be a time lag to varying degrees. The cost and benefit of public policy cannot be accurately evaluated. The uncertainties of different global systems are gradually increasing. From the institutional point of view, in order to deal with this situation of "distributed causalities", we will need to make major adjustments to the existing system of human society, and even to produce a new system.

There are more disturbing risk factors related to increasing connectivity. For a long time, the various types of contact networks have been composed of different regions in the process of globalization, and the connections between different regions are often random. With the increasing complexity of contact network systems, they will inevitably lead to the instability of the global social ecosystem. As the number of interconnected units' increases, the density of connectivity also increases. Moreover, the intensity of interactions between interconnected units increases. The probability of global social ecosystems becoming unstable will increase. The increasing complexity and connectivity, especially non-evolutionary and unplanned connectivity, will lead to reducing social ecosystem stability and increasing system vulnerability, as well as a steep increase in costs and errors [10]. The current development of the global social ecosystem is not a random network. While globalization enhances the connectivity and strength of the global social ecosystem, new connections among the components of the global social ecosystem will be continuously generated, leading to increasing systemic risks [15].

\section{Catastrophe Risk in Interconnection Threatens the Growing International Trade}

Economic globalization and trade liberalization are changing human society [22]. With the acceleration of interconnection, economic and trade activities among countries and regions in the world are more frequent. Moreover, the degrees of interdependence among economic systems are also increasing [23]. In the past 30 years, the average annual growth rate of the world's total commodity exports has been very fast. Especially since entering the 21st century, the average annual growth rate of the world's total commodity exports has greatly exceeded the average growth rate of the world's GDP. In 1990, the total export volume of world commodity trade was 3.49 trillion US dollars. In contrast, in 2019, the total export volume of world commodity trade reached 19.475 trillion US dollars, i.e., it increased more than five-fold in 30 years [20]. Take China as an example, since the implementation of reform and opening-up policy in 1978, China's foreign trade has been increasing. As of 2018, China's total foreign trade has increased more than 800 times compared with 1978. It can be expected that this number will still increase significantly in the near future [20].

Economic globalization and trade liberalization not only bring convenience and benefits to humans, but also provide channels for the rapid spread of risk factors. With the continuous development of economic globalization, different countries and regions in the world are more and more closely linked and interdependent. On the one hand, economic globalization and trade liberalization can improve the resilience of the regional and global economic system to natural disasters by increasing the substitutability of intermediate consumption. On the other hand, the increasing interdependence could lead to a greater spatial cascade effect of natural disasters, particularly in a negative way.

For example, on 11 March 2011, an earthquake with a magnitude of 9.0 occurred in the Northeast sea area of Japan and triggered a tsunami, which killed more than 15,000 people and caused direct economic losses of more than 200 billion US dollars [7]. As the third largest economy in the world at that time, Japan played an important role in the global production chains and supply chains. The economic losses caused by the earthquake had a huge impact on the related industries of the world through international trade, such as automobile manufacturing, cosmetics production, etc. The World Trade Report 2012 issued by the World Trade Organization points out that the East Japan earthquake in 2011 is one of the most important reasons that the growth rate of global trade in that year is lower than the average level of previous years [24]. In addition, the 1999 Jiji earthquake in Taiwan, China, severely damaged its Hsinchu Science and Industry Park, resulting in a sharp shortage of 
computer memory chips in the world. The Indian Ocean tsunami in 2004 caused heavy losses in tourism, shipping and other related industries in Southeast Asia. The volcanic eruption in Iceland in 2009 led to the cancellation of more than 60,000 flights around the world, which seriously affected related industries [9]. Therefore, catastrophe risk has posed severe challenges to international trade. It is urgent to analyze and manage catastrophe risk from the perspective of global risk governance and sustainable development.

\section{China's Comprehensive Disaster Defense Capability under Catastrophe Risk}

\subsection{Composition of Comprehensive Disaster Defense Capability}

The Chinese government has put forward a series of new strategies for national emergency management system and capacity building since 2012. In particular, the Chinese government emphasizes the combination of prevention, resistance and rescue, the unity of normal and abnormal disaster relief, and the transformation from focusing on post disaster relief to focusing on pre disaster prevention, from dealing with a single disaster to comprehensive disaster reduction, and from reducing disaster losses to reducing disaster risks, so as to comprehensively enhance the comprehensive prevention ability of the whole society against natural disasters. These important concepts expand the vision of China's emergency management and provide guidance for comprehensively improving the national disaster prevention and preparedness system and capacity-building. Comprehensive disaster defense capability has become an important evaluation index of national comprehensive disaster risk governance and sustainable development. Comprehensive disaster defense capability is the core embodiment of national governance capacity. From the perspective of social ecosystems and the condition of catastrophe risk governance, China's comprehensive disaster defense capability mainly includes physical defense capability, social defense capability, and humanistic defense capability (Figure 2) $[25,26]$. Physical defense capability mainly refers to the engineering structure disaster reduction and risk prevention [17,26], and it is mainly achieved by the disaster prevention construction project. Social and humanistic defense capabilities mainly refer to non-engineering functional disaster reduction and risk transfer measures [26]. The physical, social and humanistic defense capabilities of a specific region are reflected in the comprehensive disaster defense capability of the region under the comprehensive process and interaction of disaster risk system [7]. Therefore, the effective coordination of physical, social and humanistic defense capacity in a specific region is an important aspect of scientifically building inclusive disaster risk reduction capacity, and is an important foundation for strengthening comprehensive disaster risk reduction, as well as being the safety baseline of sustainable development.

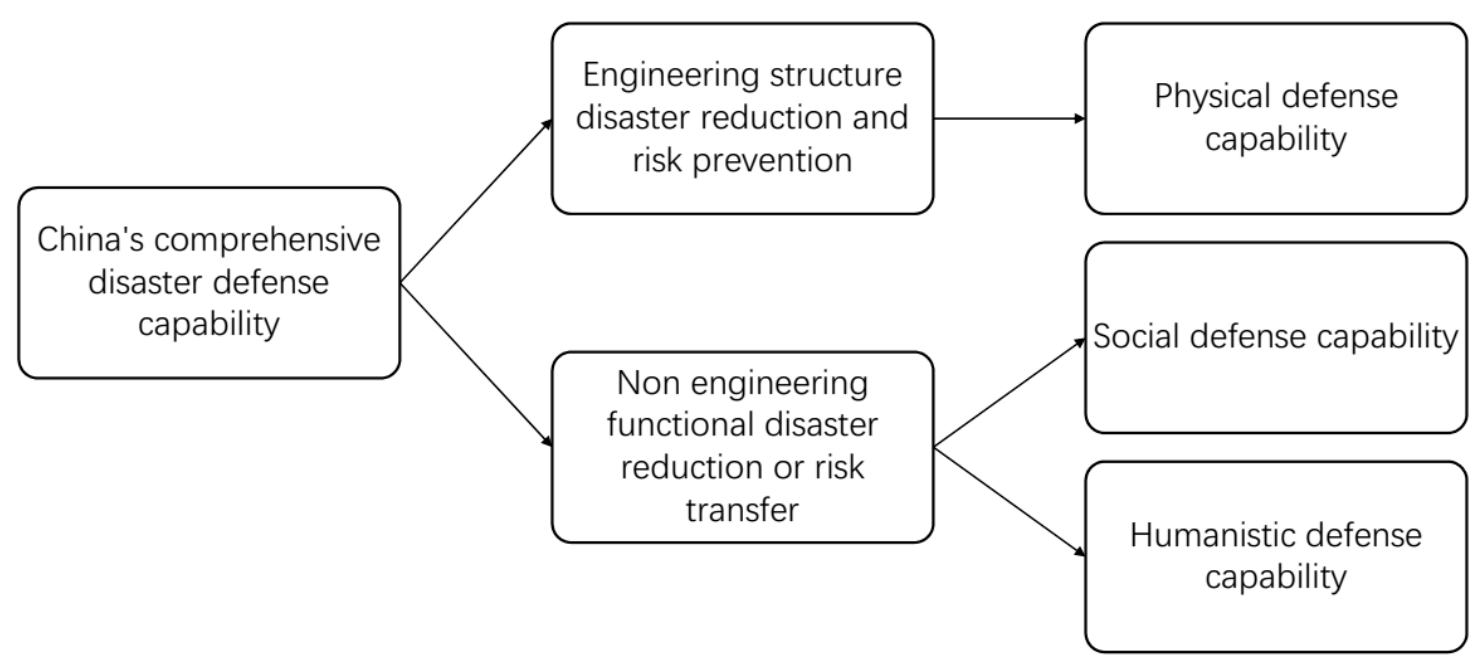

Figure 2. China's comprehensive disaster defense capability. 


\subsection{Physical Defense Capability in China}

In the past few decades, China has improved the disaster-formative environment through ecological construction, and reduced the risk of various kinds of hazards. China built various protection projects to improve the disaster risk prevention level. The main purposes of ecological construction projects, river regulation projects, major geological disaster control projects and rural drinking water safety projects in China were to reduce the risk of various hazards. The main purposes of projects involving the reconstruction of dilapidated houses for rural poor people, reinforcement of dangerous reservoirs, farmland irrigation and drainage, highway disaster prevention and control, construction and engineering facilities, fortification, reconstruction of dilapidated buildings in primary and secondary schools, etc., in China were to improve the level of disaster risk prevention [27]. In particular, the Chinese meteorological department has achieved remarkable results in the above related projects. By the end of 2017, China's meteorological department had completed the meteorological disaster risk census of all counties. The census data of 356,000 small and medium-sized rivers, 590,000 mountain torrent gullies, 65,000 debris flow points and 280,000 landslide hidden danger points had been sorted and put into storage [26]. At the same time, the compilation and application of a flood and mountain torrent risk zoning map of more than 2/3 small and medium-sized rivers in China had been completed [17].

However, there are still regional differences in the physical defense level of disaster risk in China. The overall defense levels of most cities in China are low. Except for some big cities, the seismic defense levels of general cities are lower than 7-8 intensity [10]. The antityphoon and flood control levels of most cities are lower than 50-100 years return period [7]. China's vast rural areas have few defenses against earthquakes, typhoons and floods, resulting in a relatively high vulnerability. Due to the rapid landscape and population urbanization, the vulnerability of disaster risk prevention has increased significantly in urban areas, especially in the counties and their towns, forming an urban contiguous distribution area with high vulnerability $[7,10]$. With the acceleration of urbanization and the concentration of population and wealth exposure, the high disaster risk areas in China are superimposed with the economically and socially developed areas in Middle and Eastern China. The superposition of high disaster risk, high exposure, high wealth, and high population density not only increases the disaster risk in Middle and Eastern China, but also makes the tasks of disaster risk prevention increasingly arduous. From the perspective of the expected annual GDP loss caused by natural disasters in China, most of the high disaster risk areas in the East China reach $0.85 \%$, and a few reach more than $1.0 \%$ [7]. According to Chinese statistics, under the current physical defense capability, the area of high disaster risk, medium disaster risk, and low disaster risk accounts for $2.14 \%$, $11.60 \%$, and $32.41 \%$ of the total land area of China respectively [7]. This shows that the overall disaster risk level of China is high and the regional difference is obvious [28].

Although there are still obvious regional differences, mainly reflected in the differences between the East China and the West China, as well as between urban and rural areas, China's national strength has been greatly developed and significantly improved. Therefore, according to the development and environmental characteristics, China should appropriately improve the physical defense capability level of disasters for various types of structural construction. For example, according to China's latest seismic parameter zoning, typhoon risk zoning, flood risk zoning, etc., the Chinese government can improve the fortification level of important infrastructures, such as schools, roads, pipelines, airports, ports, and warehouses, especially for lifeline facilities. The level of physical defense capability can be rapidly improved in the short term. This mainly depends on the investment of disaster risk governance funds. However, it is worth noting that the improvement of physical defense level also involves the high cost of public financial resources in the short term, and is likely to put greater financial pressure on the government. For example, China's earthquake resistance level in large cities starts at Degree VII, with a cost increase of about $20 \%$ for each step [7]. 
At present, the focus on physical defense capability can start from the establishment of the safety baseline of structural construction in high disaster risk areas. The government should formulate the physical fortification level of each major disaster type, imitate the method of compiling a seismic intensity map, and comprehensively compile the fortification level map of other major disaster types, delimit the forbidden zone of structural construction, and include it in the administrative examination and approval requirements of regional construction. At the same time, the government should limit structural construction in high disaster risk areas, especially in urban areas. The government should promote the integration of multiple plans through legislation, and formulate the proportion of public finance of governments at different levels to pay for physical defense capacity.

In general, China's physical defense capability has been significantly improved in the past decades. However, decision-makers need to pay close attention to the relationship between average defense capacity and special defense capacity in the construction of physical defense capacity. Special defense capability mainly refers to the defense capability of special time, special area, or special disaster species. The practice of comprehensive disaster reduction in China has proved that the improvement of average defense ability does not mean the improvement of special defense ability. On the contrary, special defense ability often forms the barrel effect, which affects the average defense ability. Thus, the improvement and development of physical fortification ability are affected.

\subsection{Social Defense Capability in China}

China's social defense capability has significantly improved in the past decade. China's national disaster risk communication network of early warning information served more than 1 billion people during 2015-2020, and the public coverage rate reached $87.3 \%$ by the end of 2020. The proportion of economic losses caused by meteorological disasters in GDP decreased from $3.4 \%$ in the 1990 s to $0.6 \%$ in the 2010 s [17]. The annual average deaths caused by meteorological disasters decreased to less than 2000. A four-level emergency early warning information release system has been established in China, with 16 government departments and 76 types of disaster risk early warning information. Disaster risk early warning information can reach the person in charge of emergency within $1 \mathrm{~min}$, and effectively cover the public and social media within $10 \mathrm{~min}$. In total, 2090 counties in China have formulated meteorological disaster prevention plans, and 155,000 villages have formulated meteorological disaster emergency action plans. There are 767,000 disaster risk informants in China, covering $99.7 \%$ of villages [17].

In addition, the Chinese government has greatly improved the disaster insurance coverage by mobilizing and encouraging the general public and various institutions to actively participate in various disaster insurance. Some individuals, enterprises and institutions have engaged in production and real estate development in high disaster risk areas. Compulsory disaster insurance can be implemented in accordance with related laws and regulations. In this way, while comprehensively improving the physical defense capacity of governments at all levels, the awareness and ability of disaster risk prevention of the whole society can be comprehensively improved.

In comprehensive disaster risk prevention, as the basic unit of social defense capability, the success or failure of community in the construction of social defense capability is often very important in demonstrating and warning about the significance of disasters. The government can use diversified disaster risk financing means to establish a community disaster risk prevention fund for the construction of disaster risk reduction demonstration in the community and improve the professional level of community disaster risk prevention. The government should vigorously promote the combination of communities, social workers and social organizations, effectively form the docking of carriers, talents and capital, establish a comprehensive disaster risk prevention system based on the community, build a strong social mobilization system, form a good situation of resource sharing, complementary advantages and mutual promotion, and accelerate the formation of interconnected, interactive and complementary social governance patterns between the 
government and society. In addition, the government should integrate the community's social charity resources and social assistance resources, improve the use efficiency of disaster relief resources, and reduce the prominent problems of poverty caused by disaster risks.

In addition to disaster insurance, the government should also fully consider diversified financial means such as catastrophe fund, catastrophe bond, and catastrophe lottery to prevent disaster risk. The government urgently needs to establish a national financial system to deal with catastrophe risk. Through the introduction of market mechanism and social participation, the government can establish a national catastrophe insurance system, take advantage of the advantages of social mobilization mechanisms in the information technology era, and develop diversified disaster risk financing tools.

In general, China's social defense capacity has also been significantly improved in the past decade, but there are still obvious urban-rural differences and regional differences $[7,29]$. Decision-makers need to pay close attention to the coordination, linkage, and complementarity of social defense among different regions in the construction of social defense capacity, so as to avoid the formation of a "Broken Window Effect" affecting the construction of overall social defense capacity in China.

\subsection{Humanistic Defense Capability in China}

In terms of humanistic defense, with the advent of the Internet 5G era, the communication channels and speed of disaster risk prevention and mitigation knowledge and education in new media are expected to be further improved $[17,26]$. By vigorously improving the education level of disaster risk prevention, mitigation and relief, especially the escape skills and risk prevention awareness of the general public, popularizing the exhibition of family emergency supplies, carrying out comprehensive emergency rescue drills, vigorously improving the self-help and mutual rescue ability of emergency treatment in densely populated places such as schools, hospitals, tourist scenic spots, and so on, we can build a life safety baseline and comprehensively improve society's humanistic defense capability [7].

At present, it is urgent for China to establish a national comprehensive disaster risk prevention science, technology and education system. Firstly, the Chinese government can strengthen the scientific and technological infrastructure construction of national comprehensive disaster risk prevention, such as establishing national laboratories, state key laboratories and national scientific research centers related to disaster risk prevention and mitigation. Secondly, the Chinese government can strengthen the construction of a national comprehensive disaster risk prevention discipline system, coordinate and orderly develop disaster risk science, emergency technology and risk management directions, and strengthen the talent training in three directions. Thirdly, according to national development and practical needs, the Chinese government should formulate major scientific special research projects in the field of comprehensive disaster risk prevention, promote the transformation of disaster risk cutting-edge technical knowledge, and establish a long-term mechanism to improve the popularization of disaster risk prevention and mitigation.

It is worth noting that, with the rise and prosperity of the new media of mobile Internet, the public opinion formed on the Internet after the disaster risk has yet to be effectively governed. Public opinion communication has the characteristics of rapidity, complexity and fragmentation. Once public opinion deviates from the essence of the facts, it is easy to affect the national economic security, social stability and national image. Therefore, it is necessary to attach great importance to the public opinion after a disaster.

\subsection{Summary of China's Comprehensive Disaster Defense Capability}

To sum up, comprehensive disaster defense capability reflects the ability of an emergency management system to use engineering, economic, and social resources to carry out disaster risk prevention and mitigation activities, minimize the losses caused by disasters, especially catastrophes, reduce vulnerability, and improve resilience. It includes not only the ability to reduce the risk before the disaster, but also the ability to make rapid response 
and scientific disposal in the disaster. It also includes the ability to quickly rebuild after the disaster and restore stability and prosperity before the disaster as soon as possible [26]. China's current comprehensive disaster defense capability has made greater progress than ever before. However, it is still insufficient in the face of catastrophe risk [15]. In particular, it faces severe challenges in the aspects of catastrophe chains, catastrophe impact and resource reserve capacity. Therefore, determining how to improve China's comprehensive disaster prevention capability is the key to effectively resolving catastrophe risk, which is the key issue discussed in this paper. These three challenges are also important aspects of the impact of catastrophe risk on social ecosystem, and even the whole human system in the context of interconnection and global trade development. The three challenges are related to each other. Catastrophe chains are mainly aimed at the catastrophic hazards and their dynamic and non-dynamic processes in the context of interconnection [30]. The impact of catastrophe is the potential threat to the human social ecosystem after the occurrence of a catastrophe $[16,29]$. Reserve capacity of resources is the main embodiment of human's disaster defense ability to deal with catastrophe [31-33]. The three challenges discussed here reflect the three different aspects of catastrophe risk prevention including the process of hazards, the causing of damage, and human response, and are also the important focus for China to resolve catastrophe risk [34].

\section{Key Points to Resolve the Catastrophe Risk in China}

Firstly, it is urgent to improve and strengthen the ability of decision-makers to study and judge catastrophe chains. Under the background of interconnection, the situation of catastrophe risk prevention is severe. A catastrophe causes complex and diverse secondary disasters through disaster chains, which bring severe challenges to decision-makers in disaster emergency response. For example, the tsunami triggered by the earthquake in Chile in February 2010 destroyed several coastal towns, and caused a large area of power outage, affecting $90 \%$ of the population of the country, and some areas had power outages for several days. Robbery, riots, and prison breaks became secondary disasters caused by the earthquake [7]. This situation was exacerbated by the government's initial judgment that there was no need for international assistance. Such examples of earthquakes are likely to occur internationally in the future. As a case study of an earthquake that induced secondary disasters, it also reminds decision-makers of the need to pay attention to similar situations.

Secondly, it is urgent to strengthen the ability of decision-makers to study and judge the impact of catastrophe. After the occurrence of a catastrophe, how to make a rapid and scientific judgment on the possible impact of the disaster is the key issue in the current catastrophe risk governance. Its core is to develop an effective tool to help decision-makers make correct judgment on the potential impact of such catastrophes, especially when the information is incomplete. For example, the freezing rain and snow disaster in southern China in 2008 caused serious damage and traffic disruption, causing hundreds of thousands of Chinese citizens to be unable to reunite with their relatives during the Chinese Spring Festival [15]. In the process of this catastrophe, it was difficult for government agencies to grasp the extent of the development, especially the problems caused by lifeline systems and energy systems, as well as public transport. At the same time, decision-makers need to have a comprehensive understanding of which existing risks in the current social ecosystem exceed the current decision-makers' coping capacity.

Thirdly, it is urgent to systematically evaluate the national resource reserve capacity in emergency response to catastrophes. During Hurricane Katrina in the United States in 2005, due to the lack of public transport facilities, many people were faced with being unable to evacuate before the hurricane [34]. Due to the lack of correct judgment on the impact of Hurricane Katrina, the U.S. government were finally forced to use extremely expensive methods such as helicopters or ships to evacuate people [7]. In other words, it is very important to require governments to comprehensively assess the impact of catastrophe in the shortest time, which requires the government to use the existing resources to deal with 
the catastrophe quickly and effectively. Therefore, it is necessary to develop a tool for the government, which enables the government to quickly and effectively assess whether there are enough resources to deal with the catastrophe.

\section{Conclusions}

Great changes have taken place in the social ecosystem and disaster system in the context of globalization. The degree of interconnection between different regions around the world is greater than ever before, resulting in a variety of contact networks, the most typical of which are the global production chains and supply chains, which provide diversified channels for the evolution of catastrophe risk. With the interconnection of human society, the rapid development of international trade in the past few decades has made an important contribution to the progress of human society. However, it also provides a channel for the spread of catastrophe risk. That is, with the great development of international trade, the highly connected society is facing catastrophe risk beyond the disaster area itself. The catastrophe risk of international trade under interconnection is global, systematic, and complex. Therefore, disaster defense capability has become the focus of preventing catastrophe risk.

Taking China's comprehensive disaster defense capability as an example, this paper holds that physical defense capability, social defense capability and humanistic defense capability are important components of comprehensive disaster defense capability. China's physical, social and humanistic defense capabilities have been significantly improved in recent years. However, China's current comprehensive disaster defense capability is still insufficient in dealing with catastrophe risk, especially the decision-makers' ability to study and judge the catastrophe chains and the impact of catastrophe, and national resource reserve capacity in catastrophe emergency response. Catastrophe chains are an important embodiment of the complex process of hazards in a changing environment. The impact of catastrophe is a potential threat to the social ecosystem and even the whole human system. Resource reserve capacity reflects the ability of human society to cope with catastrophe.

Therefore, there is an internal correlation between the three in terms of emergency response time, which is also a focus of resolving catastrophe risk. In the current catastrophe risk response, the government plays a leading role. Thus, how to make decision-makers understand the relationship between the three aspects is very important. Based on these, this paper puts forward three key points to resolve catastrophe risk in China: improving and strengthening the ability of decision-makers to study and judge the catastrophe chain, strengthening the ability of decision-makers to study and judge the impact of catastrophe, and systematically evaluating the national resource reserve capacity in catastrophe emergency response.

Author Contributions: F.K. (first author) and S.S. (co-first author) contributed equally to this work. All authors wrote, reviewed, and commented on the manuscript. All authors have read and agreed to the published version of the manuscript.

Funding: This research was funded by the National Basic Research Program of China, grant number 2018YFC1509001, 2019YFC1510202 and 2018YFC0806900, the National Natural Science Foundation of China, grant number 41701103, 41775078, 41801064 and 71790611, MOST Special Fund for the Fourth National Assessment Report on Climate Change, and the Beijing Social Science Foundation Project, grant number 19JDGLA008.

Institutional Review Board Statement: Not applicable.

Informed Consent Statement: Not applicable.

Data Availability Statement: No new data were created or analyzed in this study. Data sharing is not applicable to this article.

Acknowledgments: The authors would like to acknowledge the helpful comments of three anonymous referees of the journal, who have helped to improve this paper.

Conflicts of Interest: The authors declare that no conflict of interest exists. 


\section{References}

1. IPCC SREX. Managing the Risks of Extreme Events and Disasters to Advance Climate Change Adaptation; Cambridge University Press: Cambridge, UK, 2012.

2. IPCC AR5. Intergovernmental Panel on Climate Change 2013 Fifth Assessment Report (AR5); Cambridge University Press: Cambridge, UK, 2013.

3. IPCC SR1.5. Global Warming of $1.5^{\circ} \mathrm{C}$ : An IPCC Special Report on the Impacts of Global Warming of $1.5^{\circ} \mathrm{C}$ above Pre-industrial Levels and Related Global Greenhouse Gas Emission Pathways, in the Context of Strengthening the Global Response to the Threat of Climate Change, Sustainable Development, and Efforts to Eradicate Poverty; Cambridge University Press: Cambridge, UK, 2018.

4. Lewis, S.L.; Maslin, M.A. Defining the Anthropocene. Nature 2015, 519, 171-180. [CrossRef]

5. Steffen, W.; Broadgate, W.; Deutsch, L.; Gaffney, O.; Ludwig, C. The trajectory of the Anthropocene: The great acceleration. Anthropocene. Rev. 2015, 2, 81-98. [CrossRef]

6. Shi, P.; Xu, W.; Wang, J. Natural Disaster System in China, Natural Disasters in China; Springer: Berlin/Heidelberg, Germany, 2016.

7. Shi, P. IHDP/Future Earth-Integrated Risk Governance Project Series: Disaster Risk Science; Springer: Berlin/Heidelberg, Germany, 2019.

8. United Nations International Strategy for Disaster Reduction (UNISDR). Sendai Framework for Disaster Risk Reduction 2015-2030; United Nations: New York, NY, USA, 2015.

9. Meng, Y.; Yang, S.; Shi, P.; Jeager, C.C. The asymmetric impact of natural disasters on China's bilateral trade. Nat. Hazards Earth Syst. Sci. 2015, 15, 2273-2281. [CrossRef]

10. Kong, F.; Wang, Y.; Lv, L.; Meng, Y.; Shi, P. Progress and prospect of the global and complex impact of catastrophe on economy in the context of interconnection. J. Cent. China Norm. Univ. 2018, 52, 871-882. (In Chinese)

11. Alexander, D.E. Globalization of disaster: Trends, problems and dilemmas. J. Int. Aff. 2006, 59, 1-22.

12. Assmuth, T.; Mikael, H.; Benighaus, C. Integrated risk assessment and risk governance as socio-political phenomena: A synthetic view of the challenges. Sci. Total Environ. 2010, 408, 3943-3953. [CrossRef] [PubMed]

13. Figueiredo, R.; Martina, M. Using open building data in the development of exposure data sets for catastrophe risk modelling. Nat. Hazards Earth Syst. Sci. 2016, 16, 5045-5084. [CrossRef]

14. Kong, F. Better understanding positive and negative impacts of disasters on regional economies, with special reference to China. J. Contingencies Crisis Manag. 2020, 28, 419-481. [CrossRef]

15. Li, M. Study on Raising Social Fund to Redistribute Disaster Risk with Lottery and Insurance. Ph.D. Dissertation, Beijing Normal Universty, Beijing, China, 2016. (In Chinese).

16. Shi, P.; Li, M. New model of catastrophe risk transfer. China Financ. 2014, 5, 48-49. (In Chinese)

17. Kong, F. Third discussion on the basic definition and characteristics of disaster defense. J. Catastrology 2021, 36, 1-9.

18. Loh, B. Disaster risk management in Southeast Asia: A developmental approach. Asian Econ. Bull. 2005, 22, 229-239. [CrossRef]

19. Lv, X.; Han, Z. Emergency management in China: Towards a comprehensive model? J. Risk Res. 2019, $22,1425-1442$.

20. State Council of China. Review of the Authoritative Release of the Joint Prevention and Control Mechanism of the State Council. Available online: http:/ / sousuo.gov.cn/column/49276/0.htm (accessed on 25 November 2020).

21. Cutter, S.L. Resilience to what? Resilience for whom? Geogr. J. 2016, 182, 110-113. [CrossRef]

22. Amendola, K. Integrated catastrophe risk modelling. Adv. Nat. Hazards Res. 2013, 32, 1-10.

23. Bougen, P.D. Catastrophe risk. Econ. Soc. 2003, 32, 253-274. [CrossRef]

24. World Trade Organization. World Trade Report 2012; World Trade Organization: Geneva, Switzerland, 2012.

25. Kong, F.; Lv, L.; Wang, P.; Yan, X.; Wang, Y. Basic definition and characteristics of disaster defense capability. J. Catastrol. 2018, 33, $1-4$.

26. Kong, F. Re-discussion on the basic definition and characteristics of disaster defense. J. Catastrol. 2020, 35, 6-10.

27. Chen, F.; Guo, H. Disaster risks and response strategies in process of urbanization in China. In Contributing Paper to GAR; World Economic Forum: Cologny, Geneva, Switzerland, 2019.

28. Zhang, X.; Yi, L.; Zhao, D. Community-based disaster management: A review of progress in China. Nat. Hazards 2013, 65, 2215-2239. [CrossRef]

29. Xue, L. Evolution of emergency management system in China. Adm. Reform 2010, 8, 22-24. (In Chinese)

30. Smolka, A. Natural disasters and the challenge of extreme events: Risk management from an insurance perspective. Philos. Trans. R. Soc. 2006, 364, 2147-2165. [CrossRef]

31. Shi, P.; Jeager, C.; Ye, Q. Integrated Risk Governance; Springer: Berlin/Heidelberg, Germany, 2013.

32. Sharif, M.; Shu, S. The benefits of emergency reserves: Greater preference and persistence for goals that have slack with a cost. J. Mark. Res. 2017, 54, 495-509. [CrossRef]

33. United Nations International Strategy for Disaster Reduction (UNISDR). Global Assessment Report on Disaster Risk Reduction; United Nations: New York, NY, USA, 2019.

34. Wang, X.; Wang, Q.; Su, Z. Emergency materials distribution risk control. Appl. Mater. 2014, 310, 710-713. [CrossRef] 